\title{
Wear Displayed by the Scratch of Epoxy Composites Filled by Metallic Particles under the Influence of Magnetic Field
}

\author{
F. I. El-Zahraa', G. T. Abdel-Jaber' ${ }^{1}$, M. I. Khashaba' ${ }^{2}$, W. Y. Ali ${ }^{3}$ \\ ${ }^{1}$ Faculty of Engineering, Qena, South Valley University, Qena, Egypt \\ ${ }^{2}$ Faculty of Engineering, Minia University, El-Minia, Egypt \\ ${ }^{3}$ Faculty of Engineering, Taif University, Al-Taif, Saudi Arabia \\ Email: gtag100@web.de
}

Received 13 November 2015; accepted 26 February 2016; published 29 February 2016

Copyright (C) 2016 by authors and Scientific Research Publishing Inc.

This work is licensed under the Creative Commons Attribution International License (CC BY). http://creativecommons.org/licenses/by/4.0/

(c) (i) Open Access

\section{Abstract}

The tribological performance of the sliding bearings which are probably made of polymers, which is subjected to magnetic field, is of great intense. The wear of epoxy composites filled by metallic particles such as iron, copper and aluminum scratched by steel indenter is investigated. The wear scar width of the scratch was measured by an optical microscope. It was found that wear displayed by the scratch of epoxy filled by the metallic filling materials such as iron, copper and aluminum increased with increasing applied load. As the content of the metallic filling materials increased, wear slightly increased due to the reduction in cohesive stress inside the matrix as well as the epoxy transfer into the indenter surface might be responsible for that behavior. For epoxy filled by iron, when the magnetic field was applied to the contact area wear significantly decreased. Increasing the intensity of the magnetic field showed slight wear increase. Wear displayed by the scratch of epoxy filled by copper showed higher values than that observed for copper filled epoxy. Presence of the magnetic field might generate electric current at the contact area leading to an increase in the intensity of the electric static charge. Moreover, wear of epoxy filled by aluminum showed lower values than that observed for epoxy composites filled by copper and higher than that displayed by iron filled epoxy composites. Under the effect of magnetic field, wear significantly increased. This behavior could explained on the basis that the presence of magnetic field accompanied by the movement of the indenter in the epoxy composites generated electric current passing through the steel indenter which caused softening of the epoxy composites. In that condition removal of epoxy from the wear track was easier and epoxy transfer into the steel indenter was accelerated.

\section{Keywords}

Wear, Epoxy Composites, Iron, Copper, Aluminum, Magnetic Field, Scratch 


\section{Introduction}

In many of mechanical drives that perform under the influence of magnetic field it is necessary to investigate the tribological performance of the sliding bearings which are probably made of polymers considering that effect. The wear of polyamide sliding against steel in the presence of magnetic field is discussed [1]. It was found that application of magnetic field on the contact area affect wear of polyamide sliding against steel at dry and oil lubricated conditions. Dry sliding of polyamide against steel surface showed increased wear with increasing load. The lowest wear values at no magnetic field were analyzed by jasmine oil followed by sun flower, almond, olive, castor, corn, glycerine and paraffin oils. Under the application of magnetic field lowest wear values were displayed by sun flower oil followed by jasmine, castor, glycerine, olive, paraffin, almond and corn oils. For oil lubricated sliding, the polar molecules of the tested lubricating oils were much affected by the magnetic field, where they oriented themselves with the polar end directed towards the sliding surface making a close packed multi-molecular layered surface film that could protect the sliding surfaces from excessive wear.

It is well known that a magnetic field affects polar molecules, which contain ionisable groups, by augmentation of the distance interactions and modification of the angles between bonds [2]-[4]. The observed changes in the properties of polymers are attributed to the catalytic effect of the magnetic field on the molecules. Thus, the macromolecular compounds obtained in a magnetic field present higher molecular weights as compared to their homologues synthesized in the absence of the field. Thus, the utilization of continuous external magnetic fields during the reaction can lead to an improvement in some properties of the synthesized macromolecular compounds [5] [6]. Friction of polymers is accompanied by electrification. The basic mechanism of solid triboelectrification implies processes, which can be described in terms of surface conditions. During frictional interaction chemical and physiochemical transformations in polymers promote increases in the surface and bulk states density [7]. Ionization and relaxation of those states lead to electric fields of the surface and bulk charges. Electrification in friction is a common feature, it can be observed with any mode of friction, and with any combination of contacting surfaces.

The rubbing process breaks up the polymer surface and liberates free radicals and ion radicals [8]. These are highly reactive and react with oxygen dissolved in the lubricant. They are immediately transformed to peroxide and these react with the metal surface to form oxide films. The presence of a magnetic field around the ferromagnetic steel couple in sliding contact modifies considerably its tribological behavior with an important decrease in the wear rate [9]-[16]. When a magnetic field is applied, the contact in ambient air progressively became black, covered by a brittle thick black layer of oxides which leads to a low friction and a low wear mode. Polymer friction had been studied in other many work with more detailed and definition friction mechanism [17]-[29].

In the present work, the effect of magnetic field on the wear of epoxy composites filled by metallic particles scratched by a steel indenter is investigated.

\section{Experimental}

Scratch tester is consisted of a rigid stylus mount, a diamond stylus of apex angle $90^{\circ}$ and hemispherical tip as shown in Figure 1. The loading lever mounted to the stylus through three-jaw chuck. A counter weight is used to balance the loading lever Before process of loading loading. Weights of 2, 4, 6, 8 and $10 \mathrm{~N}$ are vertically applied. Resistance force of scratch has been measured using a load cell attached to the loading lever and connected to display digital monitor. The test specimen is fixed in the specimen holder which mounted in a horizontal base, this base combined with a manual driving mechanism that help moving specimen in a straight direction. The measured scratch Force during the test is used to calculate friction coefficient. Test is carried out at room temperature under dry condition. An optical microscope analysis of $\pm 1.0 \mu \mathrm{m}$ accuracy is used in order to measure scratch width. Magnetic field of flux intensities $0.2,0.4$ and $0.6 \mathrm{mG}$ is applied by a coil assembled under the steel base where the epoxy composites where fixed. Mechanisms of formation electric static charge during scratch action is shown in Figure 2, selecting of such assembly based on Amontons' law [30] [31].

Wear displayed by the scratch of epoxy filled by iron, Figure 3, increased with increasing applied load. As the load increased the depth of indenter penetration inside the epoxy matrix increased and consequently the volume of the removed material increased. As the iron content increased wear slightly increased due to the reduction in cohesive stress inside the matrix as well as the epoxy transfer into the indenter surface might be responsible for that behavior. When the magnetic field was applied to the contact area wear significantly decreased 


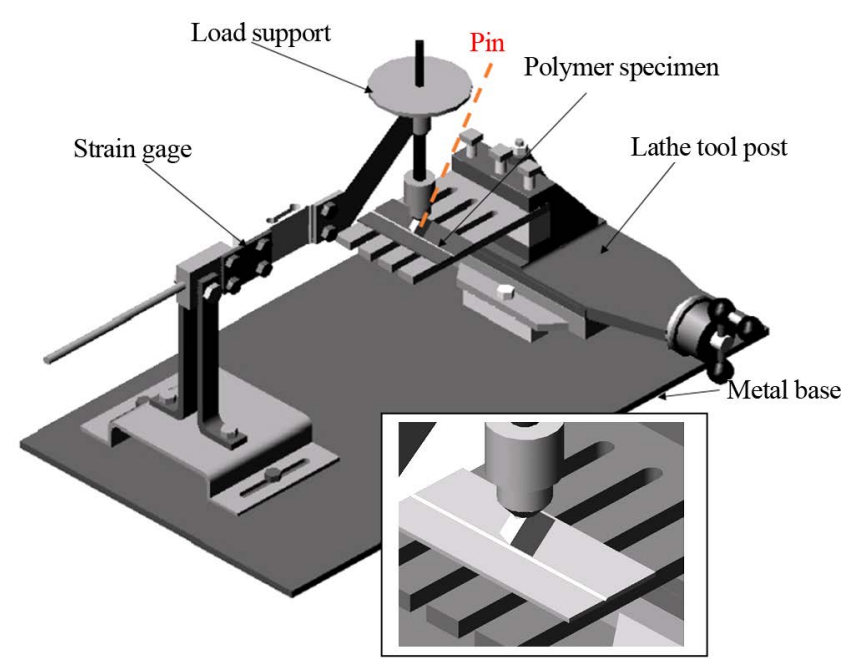

Figure 1. Details of the test rig.

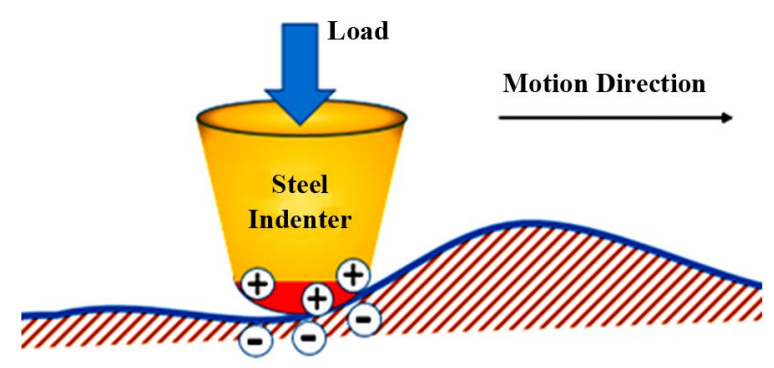

Epoxy composites

Figure 2. Formation of the electric static charge during scratch.

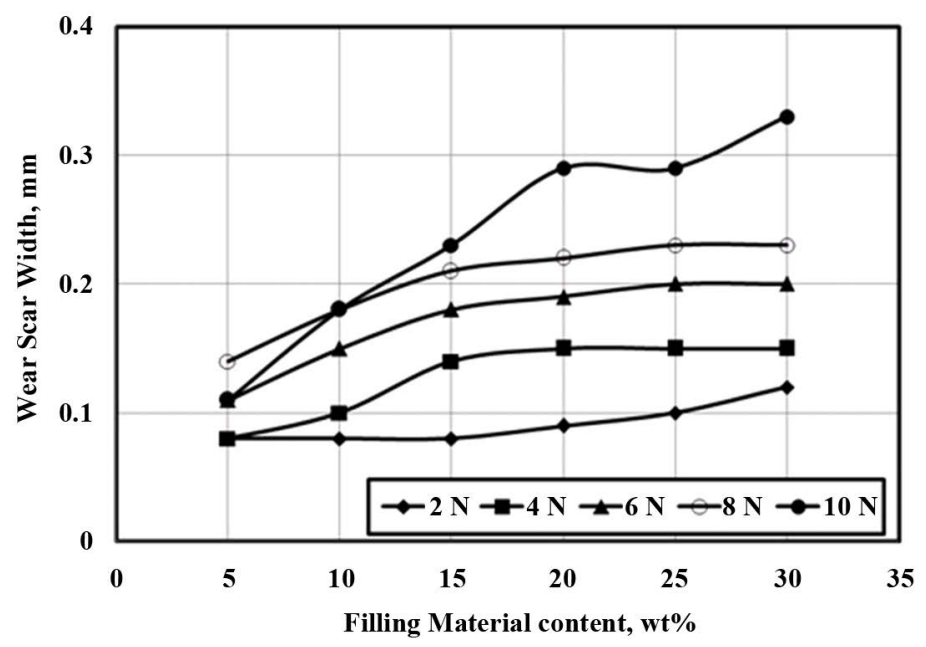

Figure 3. Wear of epoxy filled by iron.

Figure 4. This trend was attributed to the epoxy composites transfer into steel and transfer back into epoxy matrix. The magnetic field influenced the attractive force of the iron particles and increased the intensity of the electric static charge generated on the contact area.

Increasing the intensity of the magnetic field showed slight wear increase, Figure 5. It seems that the increase of the attractive force between epoxy composites and steel facilitated the removal of the epoxy.

Further increase in the magnetic field showed wear increase, Figure 6. It seems that as the magnetic field 


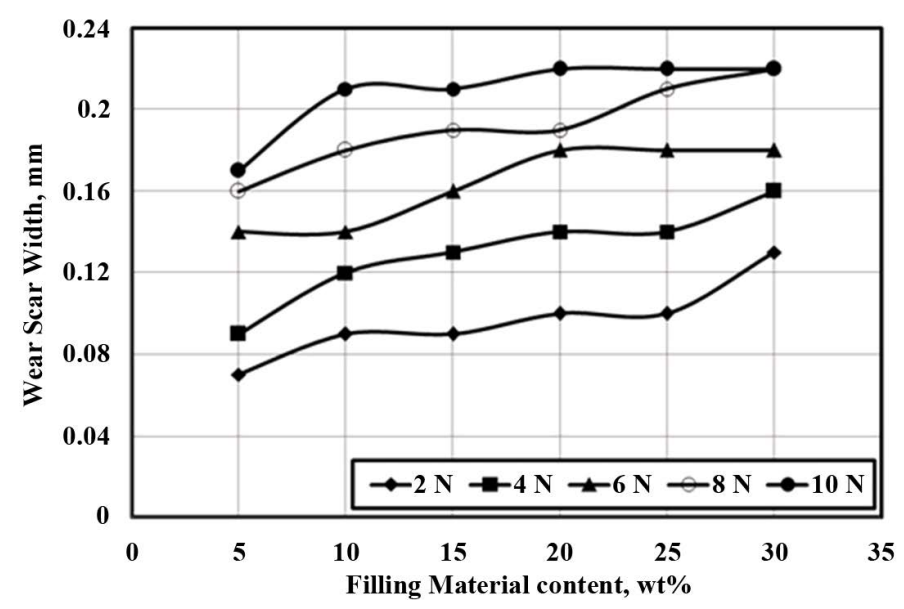

Figure 4. Wear of epoxy filled by iron under magnetic field I.

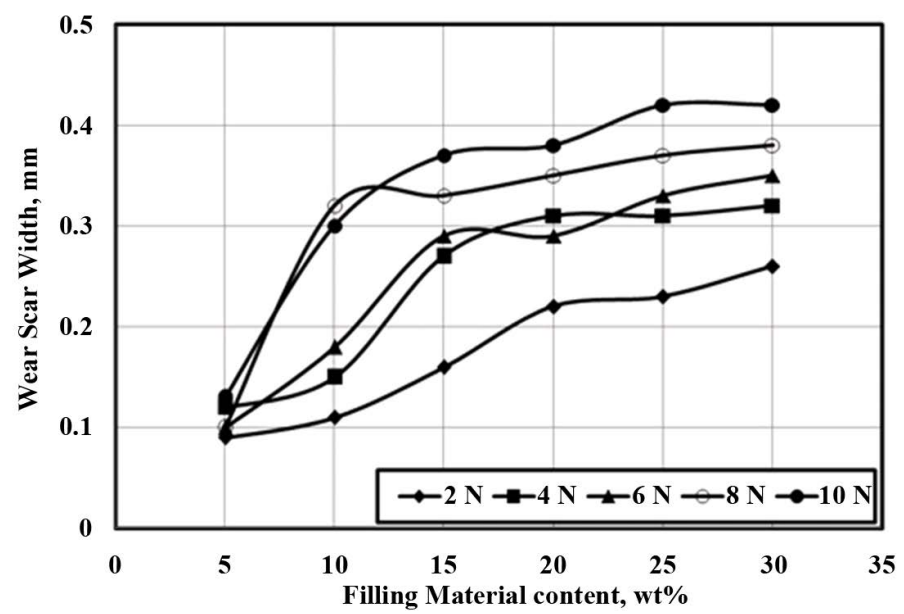

Figure 5. Wear of epoxy filled by iron under magnetic field II.

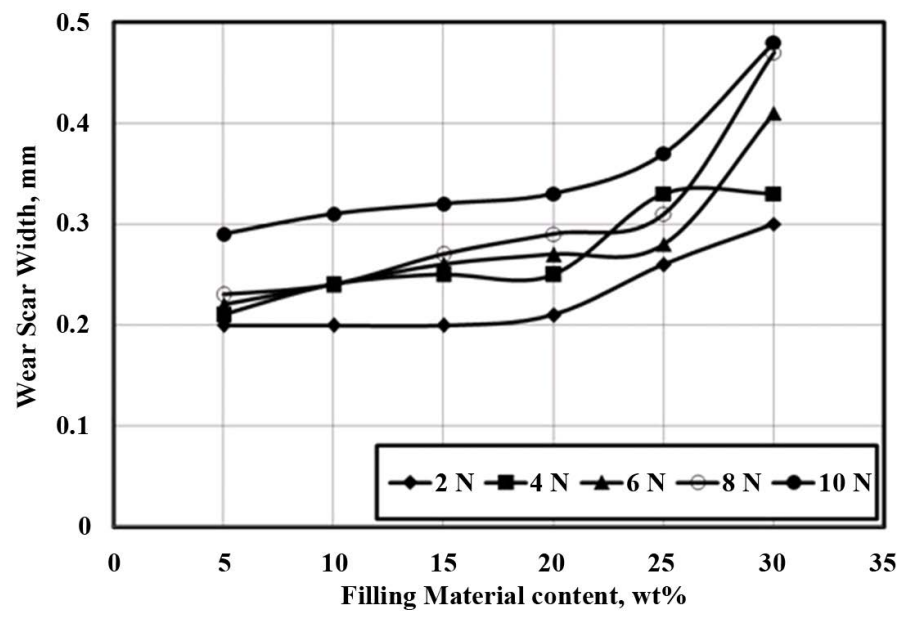

Figure 6. Wear of epoxy filled by iron under magnetic field III.

increased the attractive force between the removed material and steel surface due to the presence of iron particles. This explanation was confirmed by the higher war values observed at higher iron concentration, where the highest wear was observed at $30 \mathrm{wt} \%$ iron concentration. 
Wear displayed by the scratch of epoxy filled by copper showed higher values that that observed for iron filled epoxy, Figure 7. It is known that copper gained negative charge when slid against steel like epoxy. The resultant charge was relatively higher leading to an increase in the attractive force between removed composites materials and steel, hence the epoxy removal from the scratched area was easier.

Presence of the magnetic field might generate electric current at the contact area leading to an increase in the intensity of the electric static charge, Figure 8 . The removed epoxy filled by copper adhered strongly into the steel surface and decrease the ability of the indenter to scratch the composites and consequently wear decreased.

Wear displayed by the scratch of epoxy filled by copper under magnetic field II showed significant increase, Figure 9. This behavior can be explained on the basis that as the intensity of the magnetic field increased the generated electric current on the sliding surfaces increased. The presence of the electric current would accelerate the epoxy transfer to the steel surface leading to an increase in wear.

Further wear increase was observed in the presence of the magnetic field III, Figure 10. It is supposed that presence of magnetic field followed by the movement of the indenter in the epoxy composites generated electric current which caused softening of the epoxy composites. In that condition removal of epoxy from the wear track was easier and epoxy transfer into the steel indenter was accelerated.

Wear displayed by the scratch of epoxy filled by aluminum, Figure 11, showed lower values than that observed for epoxy composites filled by copper and higher than that displayed by iron filled epoxy composites. This performance could be attributed to the material transfer into the surface of the indenter from epoxy matrix.

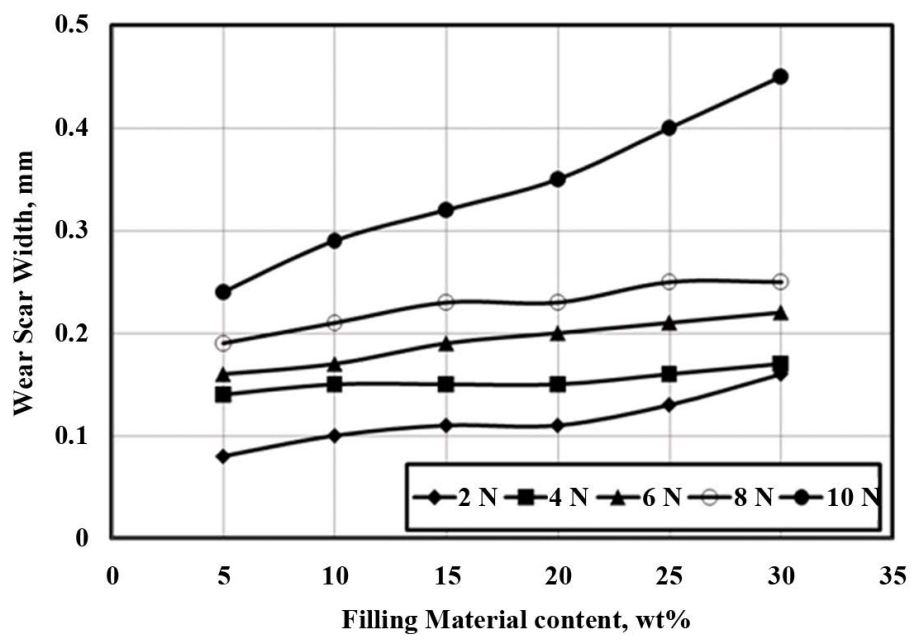

Figure 7. Wear of epoxy filled by copper.

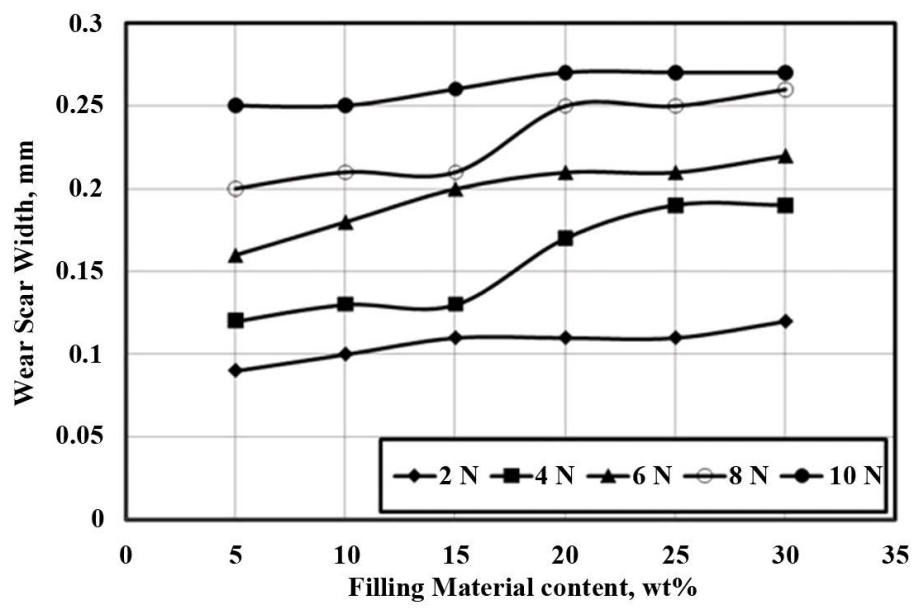

Figure 8. Wear of epoxy filled by copper under magnetic field I. 


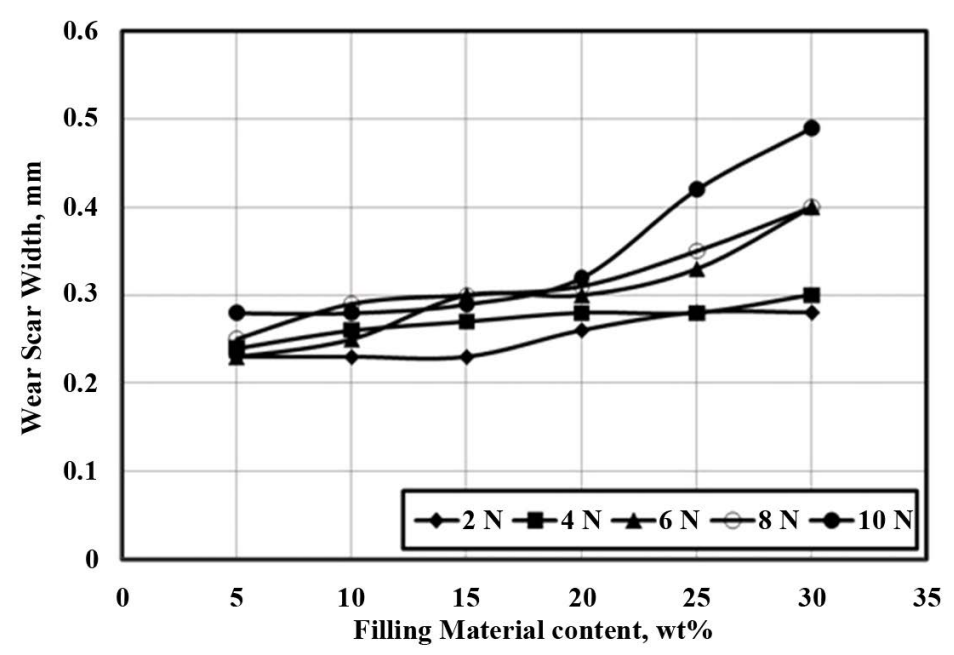

Figure 9. Wear of epoxy filled by copper under magnetic field II.

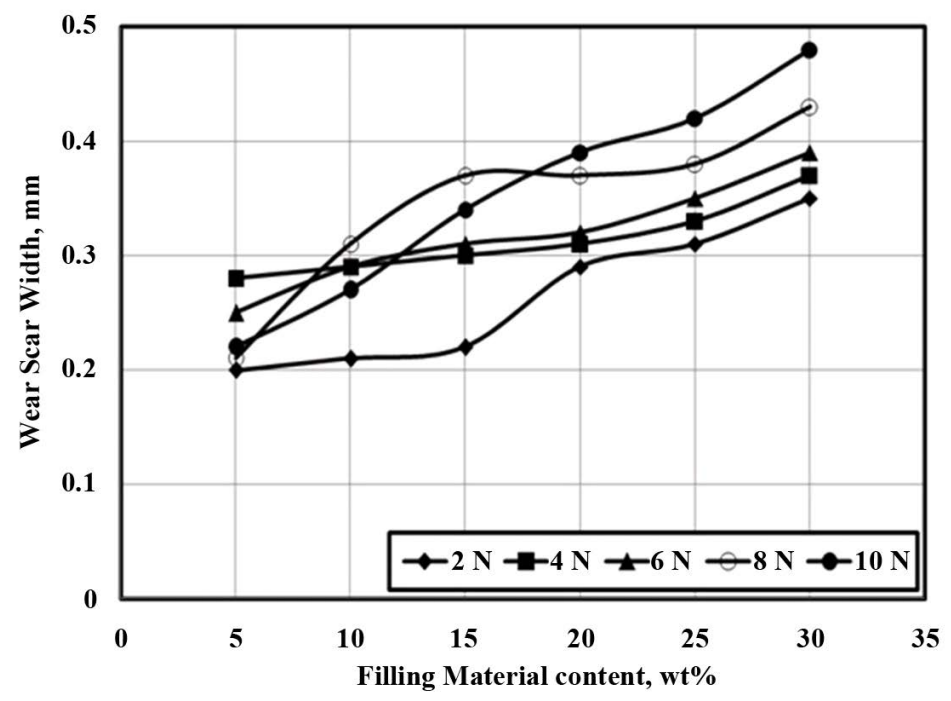

Figure 10. Wear of epoxy filled by copper under magnetic field III.

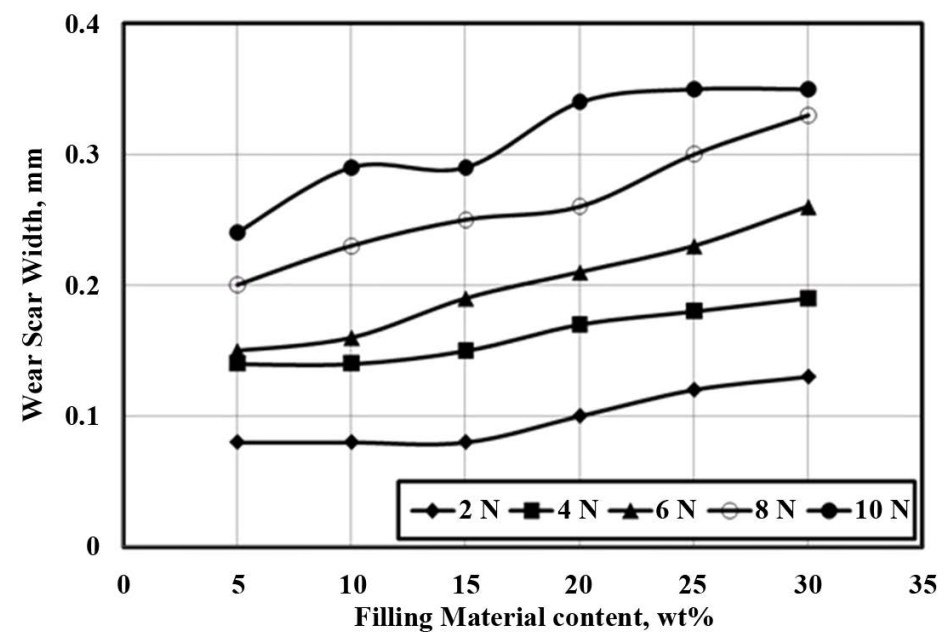

Figure 11. Wear of epoxy filled by aluminum. 
It is known that aluminum gains positive electric charge when sliding against steel, while epoxy gains negative charge. The resultant amount of electric charge would be relatively lower. In this condition the adherence of the removed epoxy composites into steel indenter would be weaker than that assumed for copper filled epoxy. The width of the wear scratch is much influenced by the cutting edge of the steel indenter as well as the adhesion of the filler into epoxy matrix.

Wear displayed by the scratch of epoxy filled by aluminum under magnetic field I, Figure 12, showed no change compared to that observed in the absence of the magnetic field. It seems that the relatively low value of the magnetic field did affect the wear behavior.

Under the effect of magnetic field II, Figure 13, wear significantly increased. This behave our could explained on the basis that the presence of magnetic field accompanied by the movement of the indenter in the epoxy composites generated electric current passing through the steel indenter which caused softening of the epoxy composites. In that condition removal of epoxy from the wear track was easier and epoxy transfer into the steel indenter was accelerated. Wear increased as aluminum content increased due to two reasons; the first was the decrease of the epoxy strength and the second was the increase of the electric conducting property of the composites.

Increasing the intensity of the magnetic field should slight decrease in wear, Figure 14. Based on this observation, it could be supposed that as the magnetic field increased the attractive force between the removed material and steel surface increased in a manner that the cutting of the steel indenter became less abrasive.

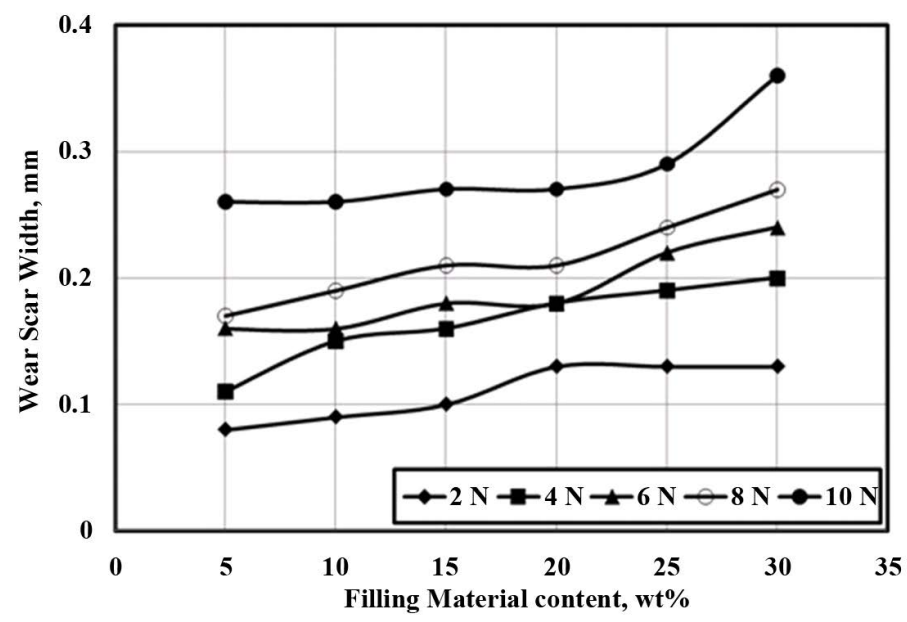

Figure 12. Wear of epoxy filled by aluminum under magnetic field I.

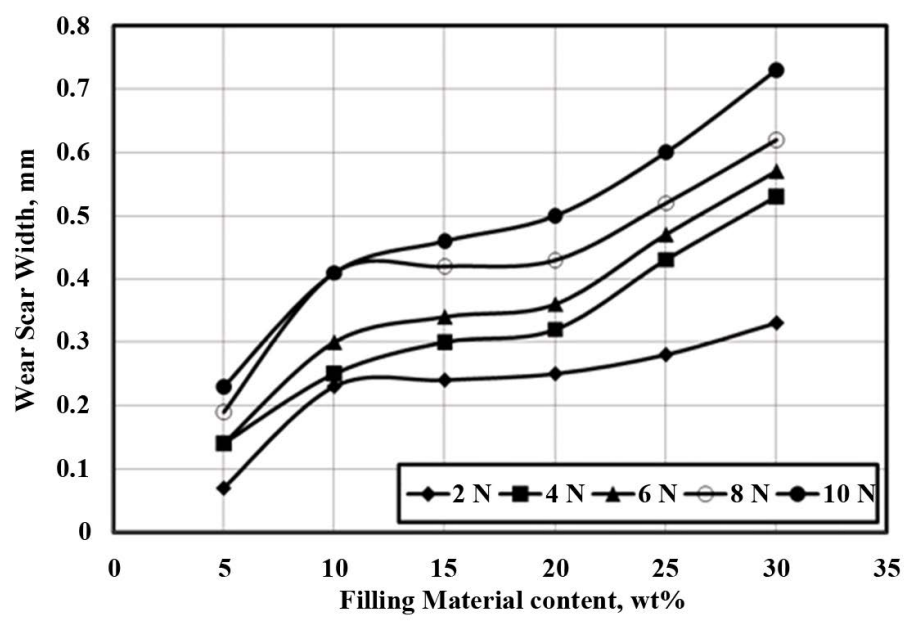

Figure 13. Wear of epoxy filled by aluminum under magnetic field II. 


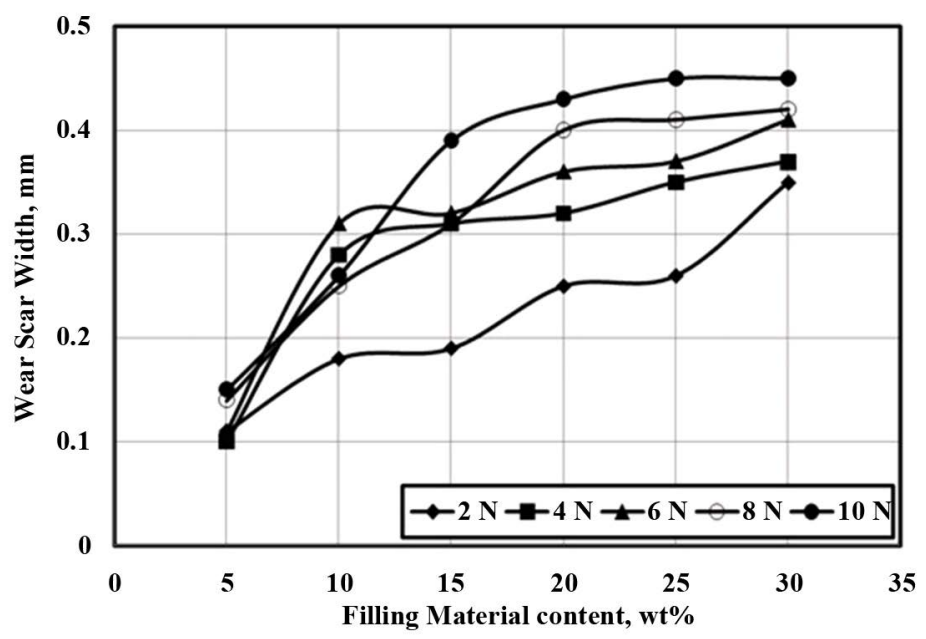

Figure 14. Wear of epoxy filled by aluminum under magnetic field III.

\section{Conclusions}

The effect of magnetic field on the sliding parties with composite material based on epoxy is studied and the following remarks have been summarized:

1) Wear of epoxy composites filled by iron increased with increasing applied load. As the iron content increased wear slightly increased. When the magnetic field was applied to the contact area, wear significantly decreased. Increasing the intensity of the magnetic field showed slight wear increase. Further increase in the magnetic field showed wear increase.

2) Wear displayed by the scratch of epoxy filled by copper showed higher values than that observed for iron filled epoxy. Presence of the magnetic field might generate electric current at the contact area leading to an increase in the intensity of the electric static charge. The removed epoxy filled by copper adhered strongly into the steel surface and decrease the ability of the indenter to scratch the composites and consequently wear decreased. Wear increased as the magnetic field increased.

3) Wear displayed by the scratch of epoxy filled by aluminum showed lower values than that observed for epoxy composites filled by copper and higher than that displayed by iron filled epoxy composites. Under the effect of magnetic field, wear significantly increased. Wear increased as aluminum content increased due to two reasons: the first was the decrease of the epoxy strength and the second was the increase of the electric conducting property of the composites.

\section{References}

[1] Abdel-Jaber, G.T., Mohamed, M.K. and Ali, W.Y. (2014) Effect of Magnetic Field on the Friction and Wear of Polyamide Sliding Against Steel. Materials Sciences and Applications, 5, 46-53. http://dx.doi.org/10.4236/msa.2014.51007

[2] Chiriac, A.P., Neamtu, I. and Simionescu, C.I. (2000) Polymerisation in a Magnetic Field, 12. A Comparative Study Regarding Some Properties of Poly (acrylamide) Synthesised in a Magnetic Field. Polymer Testing, 19, 405-413. http://dx.doi.org/10.1016/S0142-9418(99)00012-4

[3] Salikhov, K., Molin, Y., Sagdeev, R. and Buchachenko, A. (1984) Spin Polarization and Magnetic Effects in Radical Reactions. Elsevier Science, Amsterdam.

[4] Buchachenko, A., Sagdeev, R. and Salikhov, K. (1978) Magnetic and Spin Effects in Chemical Reactions. Nauka, Moscow.

[5] Liepins, R. (1996) In Polymeric Materials Encyclopedia. CRC Press, Cleveland, OH.

[6] Landee, C., Melville, D. and Miller, J. (1990) In: Gatteschi, D., Kahn, O., Miller, J.S. and Palacio, A., Eds., Magnetic Molecular Materials, Kluwer Academic, Amsterdam, Vol. 198, p. 395.

[7] Bely, V.A., Pinchuk, L.S., Klimovich, A.F. and Guzenkov, S.I. (1989) Tribological Aspects of Electret State Generation in Polymers. Proceedings of the 5th International Congress on Tribology, EUROTRIB 89, Vol. 2, 13-16 June 1989 , Espo, 276-281. 
[8] Koutkov, A.A. (1970) A Brief Summary of Recent Work on the Friction and Wear of Metals and Polymers under Boundary Conditions. Wear, 15, 294-296. http://dx.doi.org/10.1016/0043-1648(70)90020-7

[9] Muju, M. and Ghosh, A. (1977) A Model of Adhesive Wear in the Presence of a Magnetic Field. Wear, 41, $103-116$. http://dx.doi.org/10.1016/0043-1648(77)90195-8

[10] Muju, M. and Ghosh, A. (1980) Effect of a Magnetic Field on the Diffusive Wear of Cutting Tools. Wear, 58, $137-145$. http://dx.doi.org/10.1016/0043-1648(80)90218-5

[11] Hiratsuka, K. (1993) Wear of Metals in a Magnetic Field in Boundary Lubrication. In: Proceedings of the 19th Leeds-Lyon Symposium on Tribology, Elsevier, Amsterdam, 1-8. http://dx.doi.org/10.1016/S0167-8922(08)70383-3

[12] Kumagai, K., Takahashi, M. and Kamiya, O. (1992) Wear Behaviour in the Presence of Magnetic Fields for Pin-onDisc Repeated Dry Wear Tests. Tribology International, 25, 91-98. http://dx.doi.org/10.1016/0301-679X(92)90085-2

[13] Bhushan, B. (1986) Electromagnetic Effects on the Friction and Wear of Metal. Wear, 110, 256-261.

[14] Forehand, S. and Bhushan, B. (1997) In Study of Wear Mechanisms in Magnetic Thin-Film Discs. Tribology Transactions, 40, 549-558. http://dx.doi.org/10.1080/10402009708983692

[15] Paulmier, D., El Mansori, M. and Zaidi, H. (1997) Study of Magnetized or Electrical Sliding Contact of a Steel/Graphite Couple. Wear, 203-204, 148-154.

[16] Chin, K., Zaidi, H. and Mathia, T. (2005) Oxide Film in Magnetized Sliding Steel/Steel Contact Analysis of the Contact Stress Field and Film Failure Mode. Wear, 259, 477-481. http://dx.doi.org/10.1016/j.wear.2005.02.122

[17] Samy, A.M., Mahmoud, M.M., Khashaba, M.I. and Ali, W.Y. (2007) Friction of Rubber Sliding against Ceramics, II. Oil And Oil Diluted by Water Lubricated Conditions. KGK-Kautschuk Gummi Kunststoffe, 60, 693-696.

[18] Ezzat, F.H., Abdel-Jaber, G.T. and Ali, W.Y. (2006) Dry Sliding of Rubber on Glazed Ceramic Tiles. Proceedings of the 7th International Conference of Tribology, EGTRIB 7, Cairo, 27-28 December 2006, 1-9.

[19] Samy, A.M., Mahmoud, M.M., Khashaba, M.I. and Ali, W.Y. (2007) Friction of Rubber Sliding against Ceramics, I. Dry and Water Lubricated Conditions. KGK-Kautschuk Gummi Kunststoffe, 60, 322-327.

[20] Samy, A.M., Mahmoud, M.M., Khashaba, M.I. and Ali, W.Y. (2006) Friction of Rubber Sliding against Ceramics, III. Sand Contaminating the Lubricating Fluids. Proceedings of the Fourth Assiut University International Conference on Mechanical Engineering Advanced Technology for Industrial Production MEATIP 4, Assiut, 12-14 December 2006.

[21] Li, K.W., Yu, R. and Han, X.L. (2007) Physiological and Psychophysical Responses in Handling Maximum Acceptable Weights under Different Footwear-Floor Friction Conditions. Applied Ergonomics, 38, 259-265. http://dx.doi.org/10.1016/j.apergo.2006.06.006

[22] Mohamed, M.K., ElKattan, A.A. and Ali, W.A. (2012) Friction Coefficient Displayed by Rubber Sliding against Flooring Tiles. International Journal of Engineering \& Technology, 12, 144-149.

[23] El-Sherbiny, Y.M., Mohamed, M.K. and Ali, W.Y. (2011) Friction Coefficient Displayed by Footwear Walking against Rubber Floorings Fitted by Cylindrical Treads. Journal of the Egyptian Society of Tribology, 8, 1-12.

[24] El-Sherbiny, Y.M., Samy, A.M. and Ali, W.Y. (2010) Friction Coefficient of Rubber Sliding against Dusty Indoor Flooring. Journal of the Egyptian Society of Tribology, 7, 11-25.

[25] El-Sherbiny, Y.M., Hasouna, A.T. and Ali, W.Y. (2011) Friction Coefficient of Rubber Sliding against Flooring Materials. KGK-Kautschuk Gummi Kunststoffe, 64, 44-49.

[26] Hagger, A.M. and Davis, M. (1993) Short Fibre Reinforced, High-Temperature Resistant Polymers for a Wide Field of Tribological Applications. In: Friedrich, K., Ed., Advances in Composite Tribology, Elsevier, Amsterdam, 107-157. http://dx.doi.org/10.1016/B978-0-444-89079-5.50008-8

[27] Adhvaryu, A., Erhan, S.Z. and Perez, J.M. (2004) Tribological Studies of Thermally and Chemically Modified Vegetable Oils for Use as Environmentally Friendly Lubricants. Wear, 257, 359-367. http://dx.doi.org/10.1016/j.wear.2004.01.005

[28] Willing, A. (2001) Lubricants Based on Renewable Resources-An Environmentally Compatible Alternative to Mineral Oil Products. Chemosphere, 43, 89-98. http://dx.doi.org/10.1016/S0045-6535(00)00328-3

[29] Adhvaryu, A., Erhan, S.Z. and Perez, J.M. (2004) Tribological Studies of Thermally and Chemically Modified Vegetable Oils for Use as Environmentally Friendly Lubricants. Wear, 257, 359-367. http://dx.doi.org/10.1016/j.wear.2004.01.005

[30] Gerde, E. and Marder, M. (2001) Friction and Fracture. Nature, 413, 285-288. http://dx.doi.org/10.1038/35095018

[31] He, G., Muser, M.H. and Robbins, M.O. (1999) Adsorbed Layers and the Origin of Static Friction. Science, 284, 16501652. http://dx.doi.org/10.1126/science.284.5420.1650 